\title{
Aspiration pneumonitis after a 10-hour fast in a patient who had undergone subtotal gastrectomy - A case report -
}

Department of Anesthesia and Pain Medicine, Busan Paik Hospital, Inje University College of Medicine, Busan, Korea

\author{
Tae Hyung Kang, M.D., Kun-Moo Lee, M.D., Sang-Eun Lee, M.D., Young Whan Kim, M.D., \\ Se Hun Lim, M.D., Jeong-Han Lee, M.D., Soon Ho Cheong, M.D., Young-Kyun Choe, M.D., \\ Young Jae Kim, M.D., and Chee-Mahn Shin, M.D.
}

\begin{abstract}
A patient who had previously undergone a subtotal gastrectomy was scheduled for removal of a brain tumor under general anesthesia. Anesthesia was induced with lidocaine and propofol with rocuronium for neuromuscular blockade. She had fasted for 10 hours, but after mask ventilation, she aspirated gastric juice and materials. The oral cavity was suctioned promptly and the trachea was intubated. Intraoperative high $\mathrm{FiO}_{2}$ and dopamine were administrated to maintain the oxygen saturation and blood pressure. She received postoperative ventilatory care in the intensive care unit for 2 weeks. An upper gastrointestinal series and fiber endoscopy were performed but she had no obstruction and reflux esophagitis except delayed passage of the contrast media. She had no risk factors for pulmonary aspiration. As in this case, patients with previous gastrointestinal surgery should be considered preoperative workup for GI motility or pathology, and adequate premedication. (Korean J Anesthesiol 2008; 55: 376 9)
\end{abstract}

Key Words: aspiration pneumonitis, fasting time, subtotal gastrectomy.

Pulmonary aspiration of gastric contents during the perioperative period is rare, but has significant morbidity and mortality. The aspiration may occur immediately before, during, or after the actual act of endotracheal intubation. Mendelson first described acute chemical aspiration pneumonitis in 1946. ${ }^{1)}$ Since then, many studies have examined its incidence during anesthesia and preoperative patient risk factors. Fasting before elective surgery (nil per os [NPO] after midnight) is based on the historical presumption that the absence of intake of solids and fluids will minimize the gastric fluid volume at the time of anesthesia induction, thus decreasing the risk for pulmonary aspiration of the gastric contents, especially in vulnerable patients. We report a case in which aspiration pneumonitis occurred during mask fitting for intubation, although this patient had no known risk factors for gastric content aspiration and had fasted for 10 hours.

\section{Received : April 15, 2008}

Corresponding to : Kun-Moo Lee, Department of Anesthesia and Pain Medicine, Busan Paik Hospital, Inje University College of Medicine, 633-165, Gaegeum 2-dong, Busanjin-gu, Busan 614-735, Korea. Tel: 82-51-890-6520, Fax: 82-51-898-4216

E-mail: aneslkm@inje.ac.kr

\section{CASE REPORT}

A 46-year-old woman with brain tumor was scheduled for a neurosurgical procedure under general anesthesia. Her surgical history included a subtotal gastrectomy with Billroth II for stomach cancer 1 month earlier. Otherwise, her medical history and physical examination were unremarkable. Her laboratory findings were not remarkable, except an AST of 52 and ALT of 74. She received glycopyrrolate $0.2 \mathrm{mg}$ IV for premedication. Her NPO time was 10 hours.

On the day of surgery, anesthesia was induced with lidocaine and propofol with rocuronium for neuromuscular blockade. Mask fitting ventilation was performed for 90 seconds after injecting the rocuronium. When her mouth was opened, yellowish liquid was visible in her oral cavity. The oral cavity was suctioned promptly and the trachea was intubated with a 7.0-mm reinforced endotracheal tube. Her oxygen saturation $\left(\mathrm{SpO}_{2}\right)$ was $99 \%$. Quickly suction through the endotracheal tube was performed. Then a Levin tube was inserted and methylprednisolone $250 \mathrm{mg}$ was injected. Intraoperative anesthesia 
was maintained with oxygen $(1.5 \mathrm{~L} / \mathrm{min})$, nitrous oxide $(1.5$ $\mathrm{L} / \mathrm{min}$ ), sevoflurane $(1-2 \mathrm{vol} \%)$, and rocuronium.

After 2 hours of operation, the $\mathrm{SpO}_{2}$ was $95 \%$ and her arterial blood gases were $\mathrm{pH}=7.44$ and $\mathrm{PO}_{2}=74.3 \mathrm{mmHg}$ at $\mathrm{FiO}_{2}=1.0$. Hypotension occurred at $\mathrm{SpO}_{2} 90 \%$ and phenylephrine and dopamine were administered continuously. After 5 hours of operation, she was transferred to the intensive care unit. The intraoperative lung suction bottle contained $200 \mathrm{ml}$. Her estimated blood loss was $1200 \mathrm{ml}$ and fluid administration totaled $4400 \mathrm{ml}$. Her arterial blood gases were $\mathrm{pH}=7.42$, $\mathrm{PCO}_{2}=38.7 \mathrm{mmHg}, \mathrm{PO}_{2}=66.5 \mathrm{mmHg}$, and $\mathrm{HCO}_{3}=25.8$ at $\mathrm{FiO}_{2}=1.0$. A postoperative anteroposterior (AP) chest $\mathrm{x}$-ray was taken (Fig. 1).

On postoperative day 1 , the arterial blood gases were $\mathrm{pH}=$ 7.47, $\mathrm{PCO}_{2}=36.6 \mathrm{mmHg}, \mathrm{PO}_{2}=81.0 \mathrm{mmHg}$, and $\mathrm{HCO}_{3}=$ 26.9 at $\mathrm{FiO}_{2}=0.6$; she was ventilated in controlled mechanical ventilation (CMV) mode, with a tidal volume (TV) of 500 $\mathrm{ml}$, respiratory rate (RR) of $18 / \mathrm{min}$, and positive end-expiratory pressure (PEEP) of 10.

On postoperative day 2, the arterial blood gases were $\mathrm{pH}=$ $7.45, \mathrm{PCO}_{2}=40.1 \mathrm{mmHg}, \mathrm{PO}_{2}=103.2 \mathrm{mmHg}, \mathrm{HCO}_{3}=28.3$ at $\mathrm{FiO}_{2}=0.4, \mathrm{TV} / \mathrm{RR}=350 \mathrm{ml} / 16 / \mathrm{min}$, and $\mathrm{PEEP}=8 \mathrm{~cm}$ $\mathrm{H}_{2} \mathrm{O}$.

After 2 weeks, she was transferred to a general ward. An upper gastrointestinal (UGI) series and fiber endoscopy were performed. These showed signs of a post-subtotal gastrectomy with a gastrojejunostomy, with delayed passage of the contrast

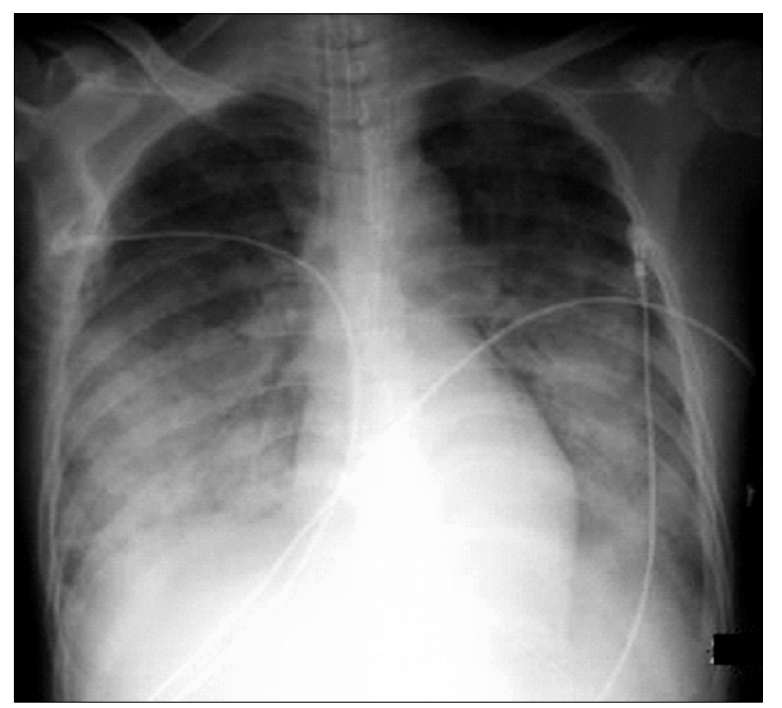

Fig. 1. The chest radiograph shows diffuse, bilateral pulmonary opacification due to the aspiration of gastric contents. media through the anastomosis site and E-loop, and no obstructions or reflux esophagitis.

\section{DISCUSSION}

Aspiration is defined as the inhalation of oropharyngeal or gastric contents into the larynx and lower respiratory tract. ${ }^{2,3)}$ Several pulmonary syndromes may follow aspiration, depending on the amount and nature of the aspirated material, the frequency of aspiration, and the host's response to the aspirated material. ${ }^{3)}$ Aspiration pneumonitis (Mendelson's syndrome) is a chemical injury caused by the inhalation of sterile gastric contents and a major cause of anesthetic mortality.

Several patient characteristics lead to the development of aspiration. These include neurologic dysphagia, disruption of gastroesophageal junction, anatomic abnormality of the upper aerodigestive tract, general anesthesia, drug overdose, extreme of age. General anesthesia may predispose patients to the aspiration of gastroesophageal contents because of depression of the protective reflex during loss of consciousness. The majority of pulmonary aspiration occurs during laryngoscopy and tracheal extubation. Aspiration pneumonitis occurs in approximately $10 \%$ of patients who are hospitalized after a drug overdose, ${ }^{4,5)}$ and is also a recognized complication of general anesthesia, occurring in approximately 1 in 3000 operations in which anesthesia is administered. When anesthesia-related aspiration occurs and leads to acute lung injury, this complication is associated with 10 to $30 \%$ of anesthesia-related deaths. ${ }^{6,7)}$ Risk factors for aspiration of gastric contents are a full stomach ( $<8$-hour fast), trauma, intra-abdominal pathology (bowel obstruction or gastric paresis), esophageal disease, pregnancy, and obesity. ${ }^{8)}$ Aspiration of acidic gastric contents can present dramatically with a full-blown picture that includes gastric contents in the oropharynx, wheezing, coughing, shortness of breath, cyanosis, pulmonary edema, hypotension, and hypoxemia, which may progress rapidly to severe acute respiratory distress syndrome and death. ${ }^{9}$ Agreement exists that a $\mathrm{pH}$ of less than 2.5 and a volume of gastric aspirate greater than $0.3 \mathrm{ml}$ per kilogram of body weight $(20-25 \mathrm{ml}$ in adults) are required for the development of aspiration pneumonitis. However, the stomach contains a variety of other substances in addition to acid. Aspiration of particulate food matter from the stomach may cause severe pulmonary damage, even if the $\mathrm{pH}$ of the aspirate is above $2.5 .^{10,11)}$ Patients are fasted before anesthesia to allow sufficient time for gastric emptying of ingested food 
and liquid at the time of anesthesia induction as the traditional preoperative fast. However, prolonged fasting does not guarantee an empty stomach at the time of induction. Furthermore, the ingestion of $150 \mathrm{ml}$ of either coffee or orange juice 2 to 3 hours before induction of anesthesia had no significant effect on residual gastric volume or $\mathrm{pH}$ in adults. ${ }^{12)}$ Arbitrary restrictions (e.g., NPO after midnight) dictating when outpatients may drink fluids before an elective operation are completely unwarranted. Nevertheless, to observe or read a description of even one case of pulmonary aspiration of gastric contents and its life-threatening potential, may motivate some practitioners to follow conservative preoperative fasting standards.

Our patient showed delayed passage of the contrast media in UGI series. The reported incidence of delayed gastric emptying after gastric surgery is $5 \%$ to $25 \%$ and will vary according to the definition for delayed gastric emptying, the patients mix, indications for operation, and the general health and nutritional status of patients. ${ }^{13-16)}$ Our patient had undergone a subtotal gastrectomy with Billroth II 1 month earlier, and surgical intervention on the stomach greatly alters gastric function and gastric emptying. A subtotal gastrectomy is now considered the treatment of choice for antral stomach cancer. Abdominal collection (3.9\%), pancreatitis/ pancreatic fistula (3.2\%), intestinal occlusion/ prolonged ileus (2.6\%), bleeding (2.3\%), wound infection $(2.3 \%)$ and anatomotic leakage $(1.9 \%)$ were the most frequent surgery-related complaints after subtotal gastrectomy with Billroth II reconstruction. ${ }^{17)}$ Billroth II reconstruction after subtotal gastrectomy for gastric cancer is associated with a limited risk of anastomotic complications, with special reference to anastomotic bleeding $(0.3 \%)$ and delayed gastric emptying of the gastric stump (1\%). ${ }^{17)}$ In Billroth II dogs, gastric emptying of low-viscosity meals was biphasic with an initial rapid emptying. The addition of nutrients to the low-viscosity meals delayed gastric emptying accompanied by a reduction in gastric and jejunal motility. A medium-viscosity glucose meal emptied significantly slower in the Billroth II dogs than in the control dogs. The results show that meal viscosity and jejunal motor pattern influence gastric emptying after Billroth II gastrectomy. ${ }^{18)}$ Our patient ate medium-viscosity meals before the day of surgery, which have a delayed gastric emptying rate compared to low-viscosity meals. Also our patient did not ambulating earlier and had prolonged hospitalization for 1 month. This is also cause of delayed gastric emptying. The esophageal reflux of the intestinal contents and swallowing dysfunction were the most important risk factors for aspiration pneumonia
Table 1. Methods to reduce the Risk of Regurgitation and Pulmonary Aspiration

\begin{tabular}{ll}
\hline 1. Minimize intake & $\begin{array}{l}\text { Adequate preoperative fasting } \\
\text { Clear liquids only if necessary }\end{array}$ \\
$\begin{array}{c}\text { 2. Increase gastric } \\
\text { emptying }\end{array}$ & Prokinetics (e.g., metoclopramide) \\
$\begin{array}{c}\text { 3. Reduce gastric } \\
\text { volume and acidity }\end{array}$ & $\begin{array}{l}\text { Nasogastric tube } \\
\text { Non-particulate antacid (e.g., sodium citrate) }\end{array}$ \\
& $\begin{array}{l}\text { H2-receptor antagonists (e.g., famotidine) } \\
\text { Proton pump inhibitors (e.g., lansoprazole) }\end{array}$ \\
4. Airway management & Cricoid pressure \\
and protection & $\begin{array}{l}\text { Cuffed endotracheal intubation } \\
\text { Esophageal-tracheal combitube } \\
\end{array}$ \\
& Proseal laryngeal mask airway \\
\hline
\end{tabular}

following gastrectomy, ${ }^{19)}$ but the severity of the symptoms of aspiration differs in total and subtotal gastrectomy because the reflux contents of a patient with a total gastrectomy do not contain gastric juice or hydrogen ions. So, preoperative workup for GI motility includes UGI series, gastric fiber endoscopy, or 24-hour esophageal $\mathrm{pH}$ monitoring for esophageal reflux and a low-viscosity meal diet

The risk factors for aspiration pneumonitis and the methods for preventing it are known (Table 1$){ }^{20)}$ A rapid-sequence induction is employed when the patient is at particular risk of aspiration and there is reasonable certainty that intubation should not be difficult. If there is sufficient doubt about the ability to intubate the patient in this setting, an intubation in the conscious patient with judicious use of topical anesthesia with or without sedation should be strongly considered.

In conclusion, patients with a history of gastrointestinal surgery should be considered preoperative workup for GI motility or pathology, and adequate premedication. If preoperative workup for GI motility may is not performed, the anesthesiologist should proceed with the assumption that the stomach is not completely empty and exercise caution when managing patients to prevent aspiration.

\section{REFERENCES}

1. Mendelson CL: The aspiration of stomach contents into the lungs during obstetric anesthesia. Am J Obstet Gynecol 1946; 52: 191-205.

2. Irwin RS: Aspiration. In: Irwin and Rippe's Intensive Care Medicine. 4th ed. Edited by Irwin RS, Cerra FB, Rippe JM: Philadelphia, Lippincott-Raven Publishers. 1999, pp 685-92.

3. Cassiere HA, Niederman MS: Aspiration pneumonia, lipoid pneumonia, and lung abscess. In: Textbook of Pulmonary Diseases. 6th 
ed. Edited by Baum GL, Crapo JD, Celli BR, Karlinsky JB: Philadelphia, Lippincott-Raven Publishers. 1998, pp 645-55.

4. Roy TM, Ossorio MA, Cipolla LM, Fields CL, Snider HL, Anderson WH: Pulmonary complications after tricyclic antidepressant overdose. Chest 1989; 96: 852-6.

5. Aldrich T, Morrison J, Cesario T: Aspiration after overdosage of sedative or hypnotic drugs. South Med J 1980; 73: 456-8.

6. Olsson GL, Hallen B, Hambraeus-Jonzon K: Aspiration during anaesthesia: a computer-aided study of 185,358 anaesthetics. Acta Anaesthesiol Scand 1986; 30: 84-92.

7. Warner MA, Warner ME, Weber JG: Clinical significance of pulmonary aspiration during the perioperative period. Anesthesiology 1993; 78: 56-62.

8. Gal TJ: Airway management. In: Miller's Anesthesia. $6^{\text {th }}$ ed. Edited by Miller RD: New York, Elsevier Churchill Livingstone. 2005, pp 1617-52.

9. Gibbs CP, Modell JH: Pulmonary aspiration of gastric contents: pathophysiology, prevention, and management. In: Miller's Anesthesia. 4th ed. Edited by Miller RD: New York, Churchill Livingstone. 1994, pp 1437-64.

10. Schwartz DJ, Wynne JW, Gibbs CP, Hood CI, Kuck EJ: The pulmonary consequences of aspiration of gastric contents at $\mathrm{pH}$ values greater than 2.5. Am Rev Respir Dis 1980; 121: 119-26.

11. Knight PR, Rutter T, Tait AR, Coleman E, Johnson K: Pathogenesis of gastric particulate lung injury: a comparison and interaction with acidic pneumonitis. Anesth Analg 1993; 77: 754-60.
12. Hutchinson A, Maltby JR, Reid CR: Gastric fluid volume and $\mathrm{pH}$ in elective inpatients. I. Coffee or orange juice vs overnight fast. Can J Anaesth 1988; 35: 12-5

13. Kraft RO, Fry WJ, DeWeese MS. Postvagotomy gastric atony. Arch Surg 1964; 88: 865-74

14. Hermann G, Johnson V. Management of prolonged gastric retention after vagotomy and drainage. Surg Gynecol Obstet 1970; 130: $1044-8$

15. Cohen AM, Ottinger LW. Delayed gastric emptying following gastrectomy. Ann Surg 1976; 184: 689-96

16. Jordan GL, Walker LL. Severe problems with gastric emptying after gastric surgery. Ann Surg 1973; 177: 660-8

17. Pedrazzani C, Marrelli D, Rampone B, De Stefano A, Corso G, Fotia G, et al: Postoperative complications and functional results after subtotal gastrectomy with Billroth II reconstruction for primary gastric cancer. Dig Dis Sci 2007; 52: 1757-63.

18. Ehrlein HJ, Wulschke S, Thoma G, Schumpelick V: Gastrointestinal motility and gastric emptying after Billroth II gastrectomy in dogs. Dig Dis Sci 1989; 34: 1199-210.

19. Pellegrini CA, DeMeester TR, Johnson LF, Skinner DB: Gastroesophageal reflux and pulmonary aspiration: incidence, functional abnormality, and results of surgical therapy. Surgery 1979; 86: 110-9.

20. Ogunnaike BO, Whitten CW: Anesthesia and gastrointestinal disorders. In: Clinical Anesthesia. 5th ed. Edited by Barash PG, Cullen BF, Stoelting RK: Philadelphia, Lippincott Williams \& Wilkins. 2006, pp 1053-60. 